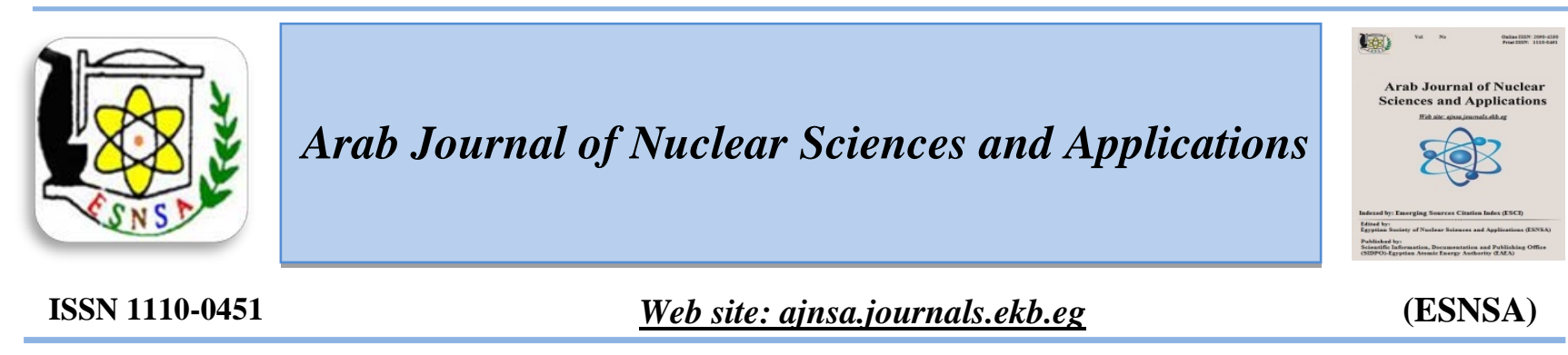

\title{
Environmental Impact of Conventional Power Plant in Normal and Accidental Conditions
}

\author{
F.S. Tawfik, N. Nassar and M.A.H. Abdel Aziz \\ Nuclear \& Radiological Regulatory Authority (ENRRA), Cairo, Egypt
}

Received $20^{\text {th }}$ Sep 2017 The prevention and simulation of chemical leakage has become one of the most important topics in the Accepted 19 ${ }^{\text {th }}$ Oct 2017 fields of environmental protection and process safety. Thermal Power plants are the major source of generation of electricity for any developing country. A power plant can affect the environment during its construction and its operation. These effects, or impacts, can be either temporary or permanent. A power plant and its auxiliary components (e.g. natural gas pipelines, water intakes and discharge, coal delivery and storage systems, new transmission lines and waste disposal sites) occupy space on the ground and in the air, use water resources, and, in most cases, emit pollutants into the air.

Before construction of any electric facility it is required to study its impact on the environment. The environmental impact study shall cover the impact of the plant on the environmental in case of normal operation and accident condition through air. This paper covers the analysis of the meteorological parameters and calculates the concentration of pollutants emitting from two stacks of Electric StationPower Plant, Damanhur, Egypt by simulating seasonal dispersion of pollutant. This plant uses mainly natural gas as fuel. The most likely pollutants emitted from the stack of the plant are nitrogen oxides, carbon monoxide, sulfur oxides, and particulate matter.

For normal emission the AirPacts module was used in the Simplified Approach for Estimating Impacts of Electricity Generation (SIMPACTS) to calculate the physical impacts and the associated damage costs for the following types of pollutants namely, sulfur dioxide $\left(\mathrm{SO}_{2}\right)$, nitrogen oxides $\left(\mathrm{NO}_{\mathrm{x}}\right)$, carbon monoxide (CO).

For risk assessment, the Hybrid Single-Particle Lagrangian Integrated Trajectory (ALOHA) Model was used with different scenarios. Through this study, dispersion models are derived for nitrogen dioxide and methane concentrations for different scenarios, which result from the fuel combustion process, to determine the distance to a defined toxic endpoint and develop a prevention/emergency response program accordingly.

Key words: Air pollutants, SIMPACTS, AirPacts, ALOHA, Electric Power Plant.

\section{Introduction}

Damanhour power station site is located $4.5 \mathrm{~km}$ to the northwest of the city of Damanhour (Fig.1). The existing power station site encompasses a total area of approximately $412,000 \mathrm{~m}^{2}$. This includes $240,000 \mathrm{~m}^{2}$ for the new Damanhour CCGT generating units inclusive of all supporting structures and administrative buildings. The existing power station consists of the following older generating units: 3x65 MWe heavy fuel oil fired plants; one 300 MWe gas fired plant; one 158
MW Combined Cycle Gas Turbine which consists of 4 gas turbines (25 MW each) and one steam unit (58 MW) [1]. The proposed power plant is a 1,800 MWe Combined Cycle Gas Turbines (CCGT) comprising two 900 MWe modules. Each module will include two gas turbines, each with a nominal electricity generating capacity of 300 megawatts (MWe) and two heat recovery steam generators (HRSG) feeding one steam generator with a nominal electricity generating capacity of

Corresponding Author: nagwa2009200@yahoo.com

DOI: $10.21608 / a j n s a .2018 .6512$

(C) Scientific Information, Documentation and Publishing Office (SIDPO)-EAEA 
300MWe. The overall generating capacity of the power plant will be $1800 \mathrm{MWe}$.

A more significant concern is the nitrogen dioxide $\mathrm{NO}_{\mathrm{x}}$ and Sulpher dioxide $\mathrm{SO}_{2}$ emissions from power plants that burn coal or natural gas. These compounds are part of a complex chemical reaction in the atmosphere that creates nitrate- and sulfate-based fine particulates.

\section{Materials and Methods}

The first step is concerned with the analysis of hourly meteorological data in the area. This meteorological data includes, wind speed, wind direction, atmospheric stability classes, mixing layer and ambient temperature.

\section{Meteorological analysis of the site}

Climate and Meteorology Data were available from the Damanhour climate monitoring station of the Egyptian Meteorological Authority. The Climate in the study area (Zawyet Ghazal, Damanhour, Elbeheria Governorate) is semi-arid. The total annual rainfall is $99.6 \mathrm{~mm}$ per year. The maximum rainfall values are recorded in December and January ranging between $22.3 \mathrm{~mm}$ and $35.1 \mathrm{~mm}$. Atmospheric temperature: The minimum temperature values are recorded during January and February $\left(\begin{array}{lll}7.6 & \mathrm{C}^{\circ}\end{array}\right)$. Maximum temperatures occur during the period of July/August, the highest temperature value of 32.1 $\mathrm{C}^{\circ}$ is recorded in July. The annual mean temperature is $19.4^{\circ} \mathrm{C}$. Wind is most frequently from North and North West directions during most of the year as in Table 1.

Relative humidity is almost stable all over the year ranging from 65 to $85 \%$ with an average of about $70 \%$. Low values occur in the autumn. Precipitation is highest in December, January and February. The total annual rainfall is $99.6 \mathrm{~mm}$ per year. Wind, in the study area, is most frequently from North and North Westerly directions. The wind roses wind speed frequency distribution are plotted to determine the prevailing wind direction and the highly polluted area for the 12 months of the year 2014 are shown in Figures (2) to (13). The Stability Class for the year 2014 is illustrated in Figures (14) to (25).

\section{Normal emissions}

In this section, a detailed estimation of emissions during normal operations is presented. Nitrogen dioxide is the only significant pollutant emitted to the atmosphere from a gas fired power plant, which induces human health effects. The other combustion products of natural gas are $\mathrm{CO}_{2}$ and $\mathrm{H}_{2} \mathrm{O}$. When fuel oil is burnt, $\mathrm{SO}_{2}$ and particulate matter become significant emissions of concern.

For normal operation conditions, it is necessary to build up an air pollution model to identify and assess dispersion from potential air pollution sources at the site.

The potential impact of air pollution emissions from various sources can be explored through analysis of models under some simplifying assumptions. Under certain conditions, the mean concentration $\mathrm{C}$ of a pollutant emitted from any type of source (point, area or volume) can be solved numerically. Numerical models such as SIMPACTS plume model [2, 3] is accepted by IAEA and is widely used to estimate and predict the concentration of different pollutants dispersed in the atmosphere. The result is used to predict the impact of different sources such as industrial sources to population and surrounding area.

SIMPACTS calculates the physical impacts and the associated damage costs for the following type of pollutants: particulate matter (PM), sulfur dioxide (SO2), nitrogen oxides (NOx), carbon monoxide (CO), and secondary species such as nitrate and sulfate aerosols. The primary or precursor pollutants (PM, SO2, NOx and $\mathrm{CO}$ ) are emitted directly into the air at the source location. Regional concentrations can be predicted using Eulerian or Lagrangian transport models such as the Windrose .The program consists of separate modules (AirPacts module) for estimating the impacts resulting from routine atmospheric emissions of pollutants from energy facilities. Input and output data of the SIMPACTS are shown in Fig. (26).

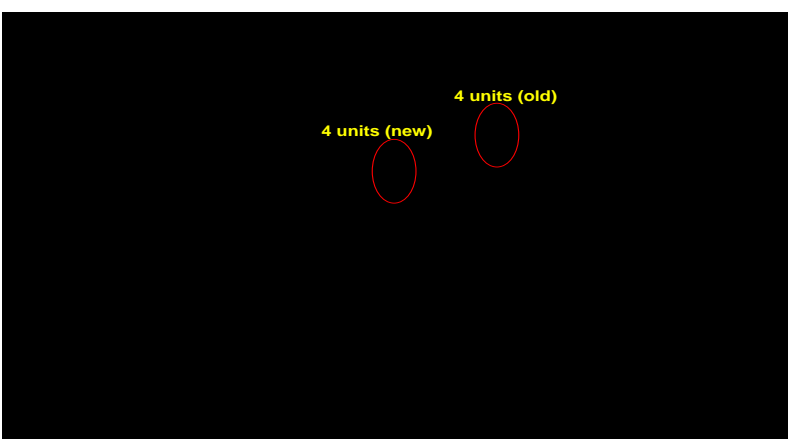

Fig. (1): Layout of Damanhour Electric Station -Power Plant, Alex Egypt 
Table (1) average Minimum and maximum temperature Damanhour climate monitoring station

\begin{tabular}{|l|l|l|l|l|l|l|l|l|l|l|l|l|l|}
\hline & Jan & Feb & Mar & Apr & May & Jun & Jul & Aug & Sep & Oct & Nov & Dec & $\begin{array}{l}\text { Annual } \\
\text { Average }\end{array}$ \\
\hline $\begin{array}{l}\text { Avg. } \\
\text { (Max) }\end{array}$ & 19.4 & 20.3 & 22.6 & 26.3 & 19.9 & 31.7 & 32.1 & 32 & 31.2 & 29.2 & 25.2 & 21 & 26.6 \\
\hline $\begin{array}{l}\text { Avg. } \\
\text { (Min) }\end{array}$ & 7.6 & 7.7 & 7.5 & 12 & 15.4 & 18.6 & 20.3 & 20.6 & 19 & 16.7 & 13.7 & 9.5 & 14.2 \\
\hline
\end{tabular}

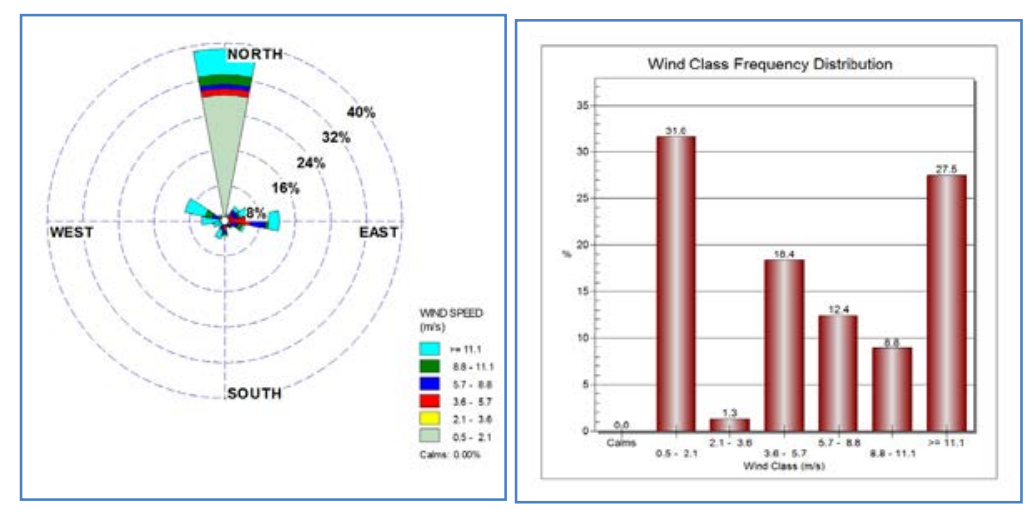

Fig. (2): Wind-rose and wind speed frequency distribution for January 2014

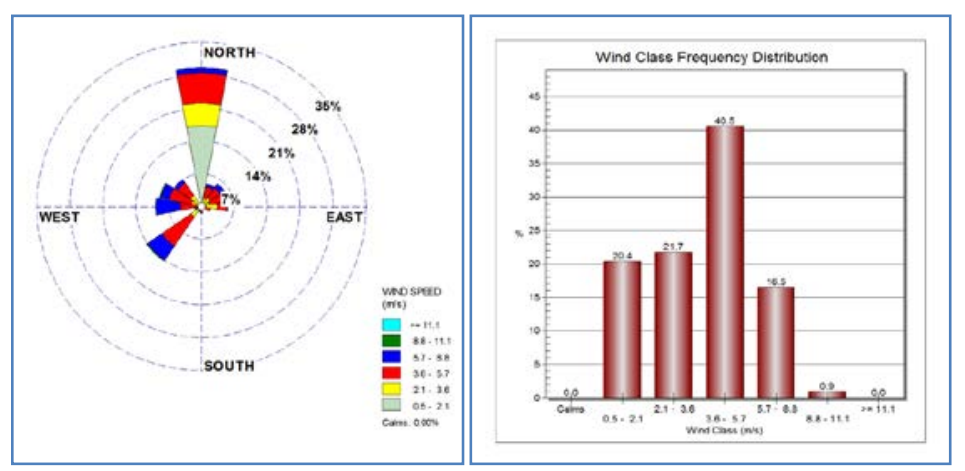

Fig. (3): wind-rose and wind speed frequency distribution for February 2014

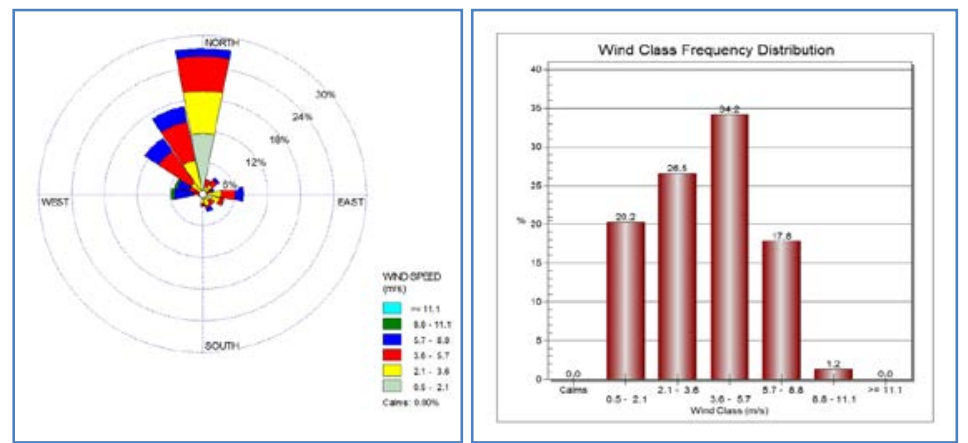

Fig. (4): wind-rose and wind speed frequency distribution for March 2014 


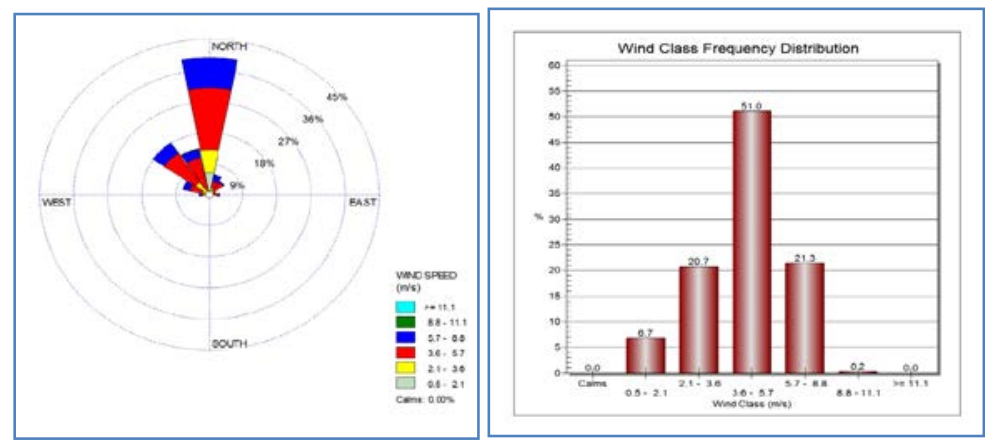

Fig. (5): wind-rose and wind speed frequency distribution for April 2014

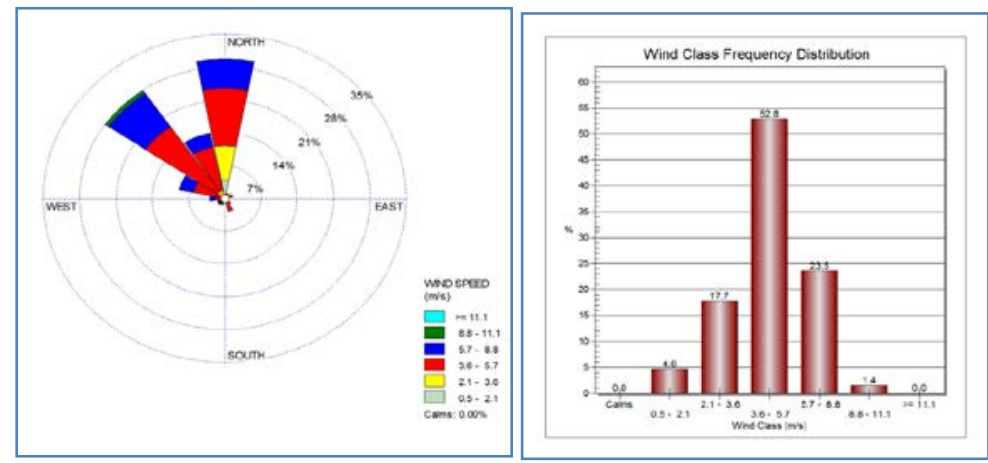

Fig. (6): wind-rose and wind speed frequency distribution for May 2014

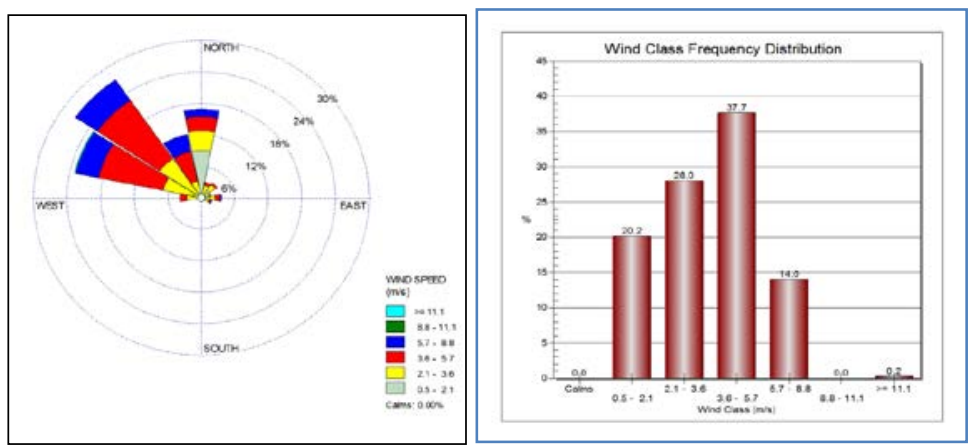

Fig. (7): wind-rose and wind speed frequency distribution for June 2014

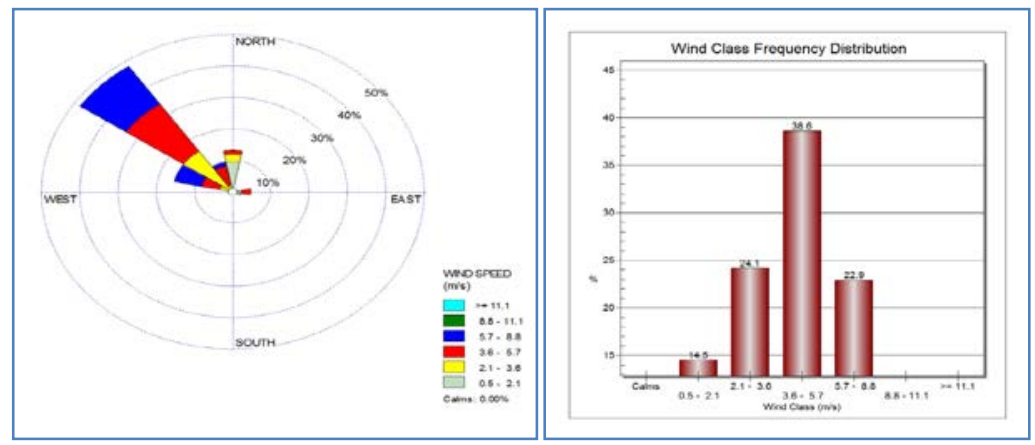

Fig. (8): wind-rose and wind speed frequency distribution for July 2014 


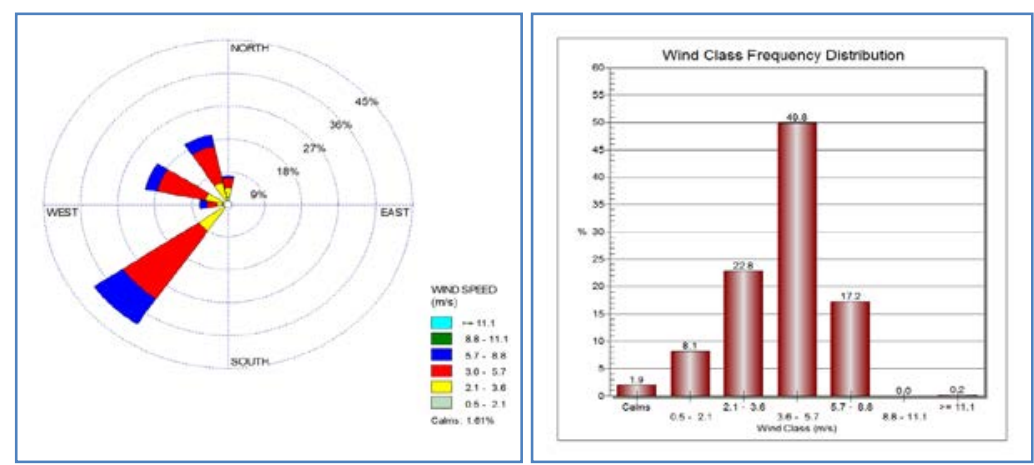

Fig. (9): wind-rose and wind speed frequency distribution for August 2014

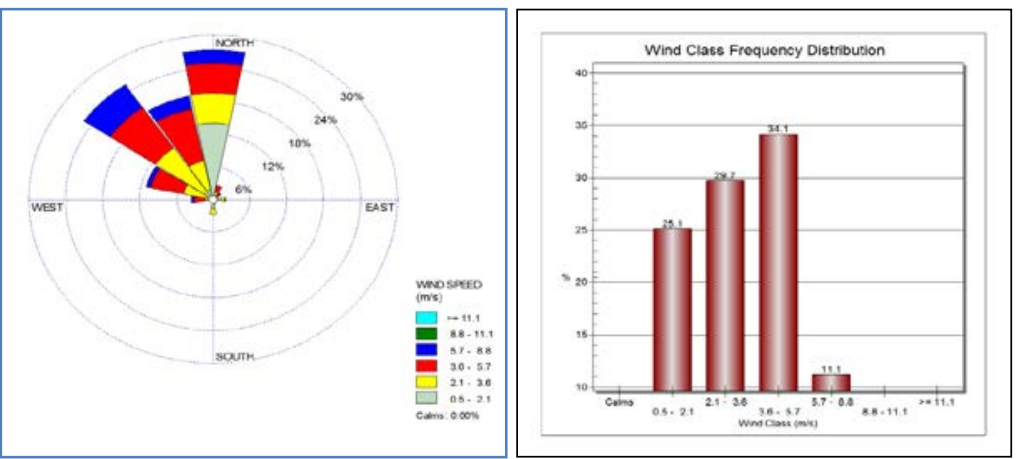

Fig. (10): wind-rose and wind speed frequency distribution for September 2014

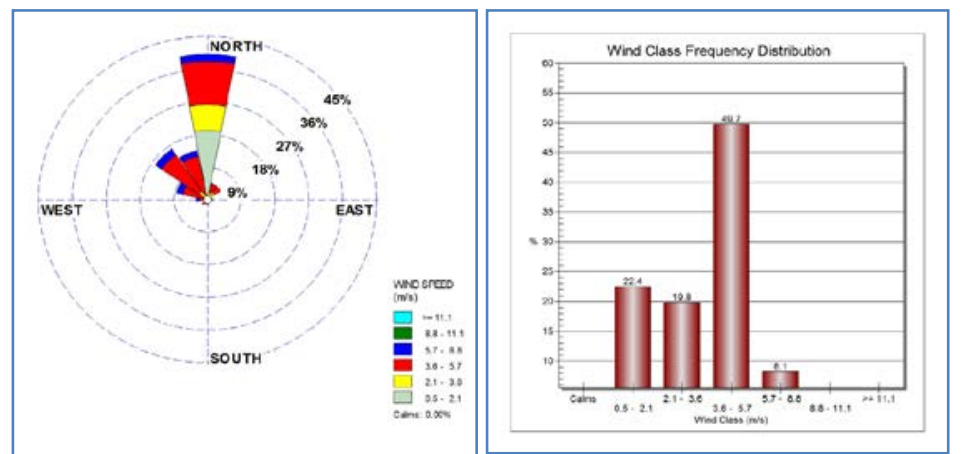

Fig. (11): wind-rose and wind speed frequency distribution for October 2014

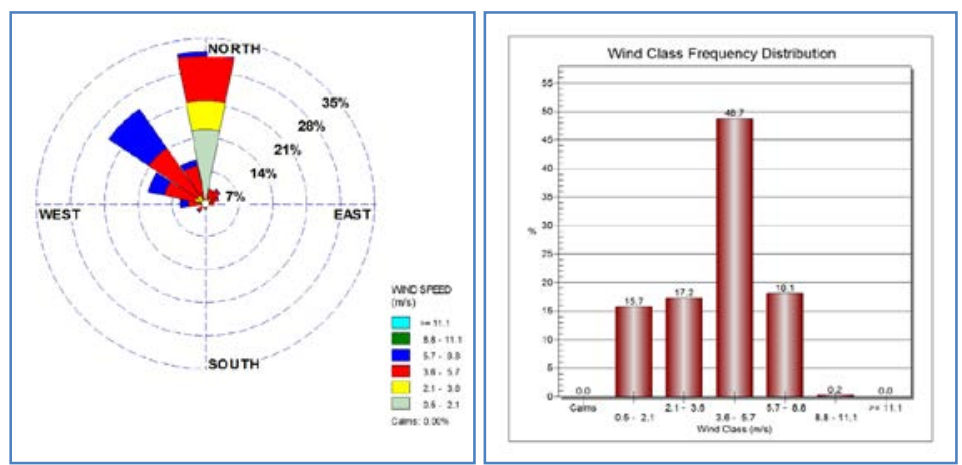

Fig. (12): wind-rose and wind speed frequency distribution for November 2014 


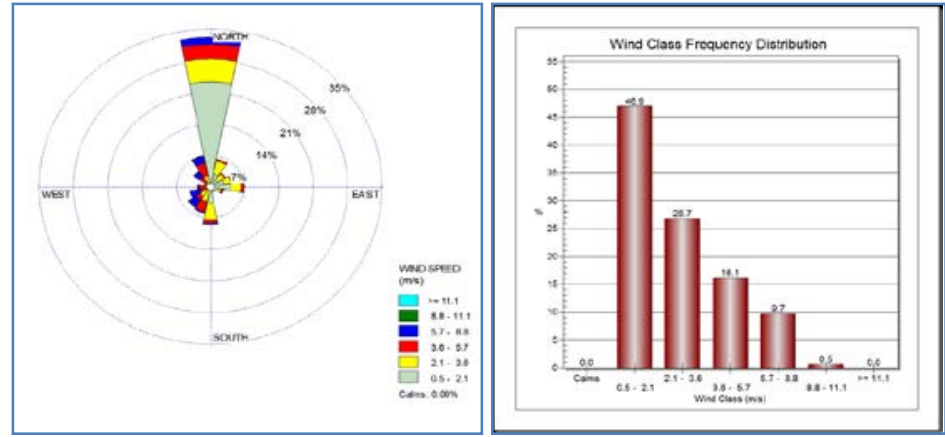

Fig. (13): wind-rose and wind speed frequency distribution for December 2014
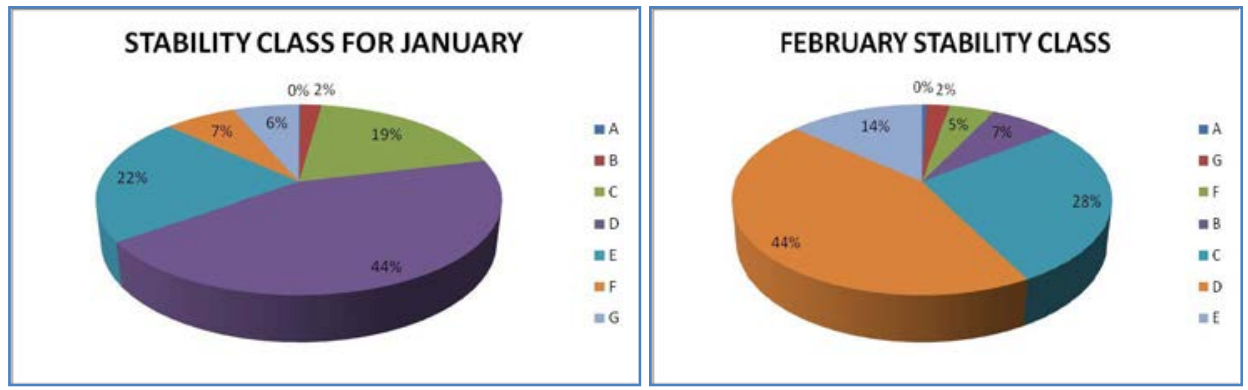

Fig. (14): Stability Class for January 2014

Fig. (15): Stability Class for February 2014

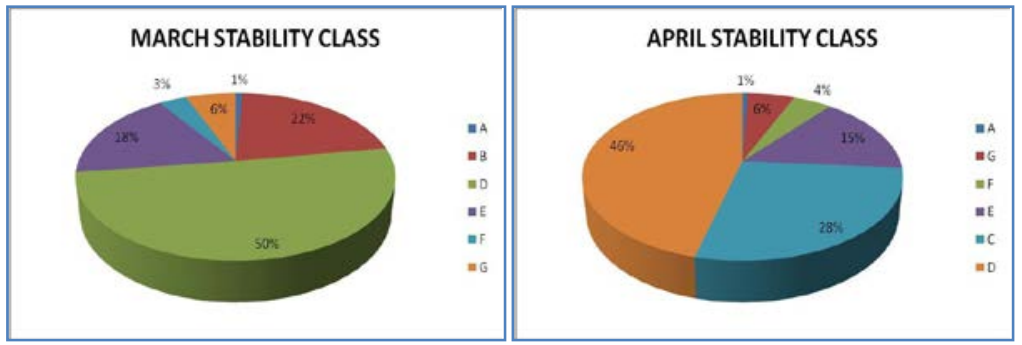

Fig. (16): Stability Class for March 2014 Fig. (17): Stability Class for April 2014

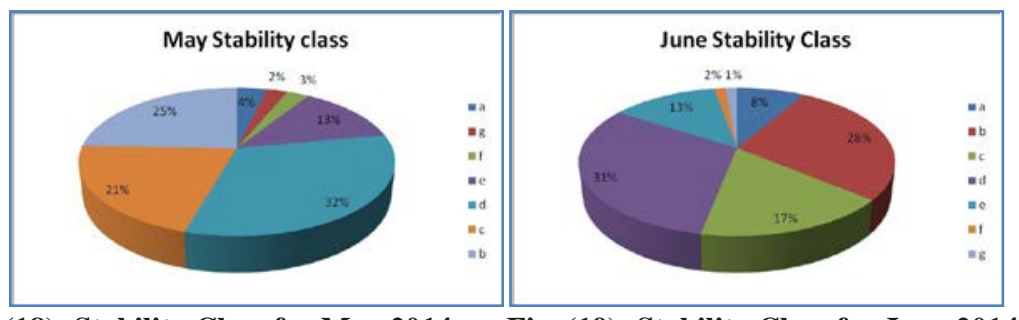

Fig. (18): Stability Class for May 2014

Fig. (19): Stability Class for June 2014

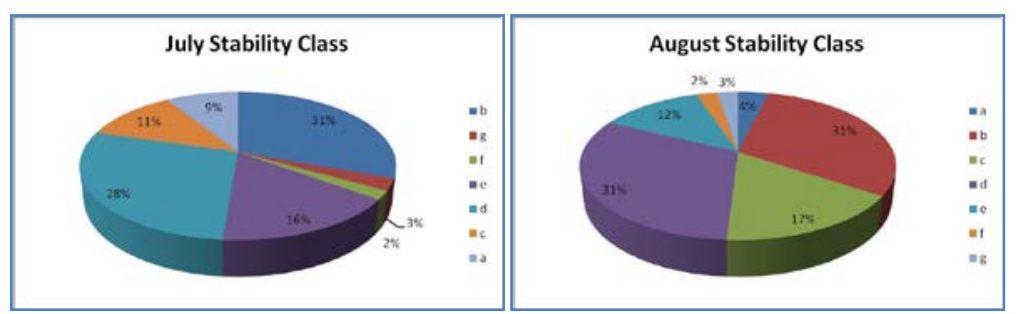

Fig. (20): Stability Class for July 2014 Fig. (21): Stability Class for August 2014 


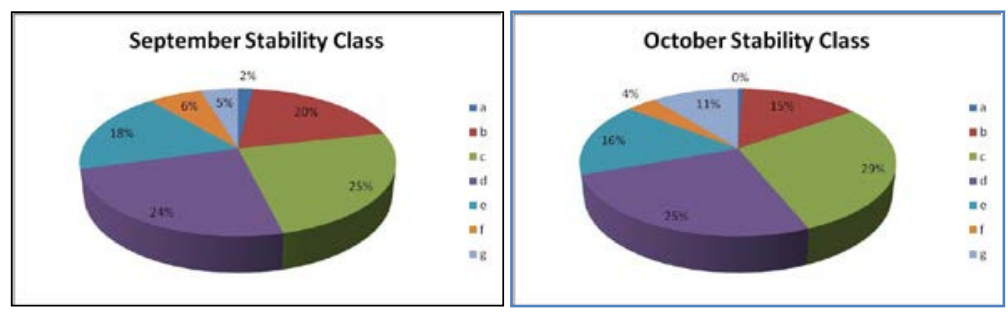

Fig. (22): Stability Class for September 2014 Fig. (23): Stability Class for October 2014

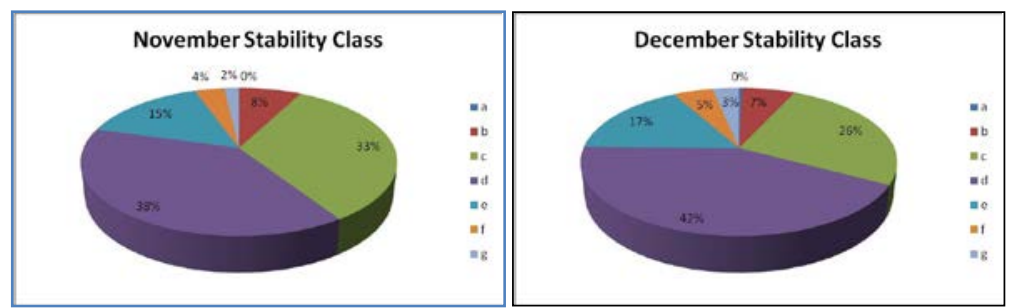

Fig. (24): Stability Class for November 2014. Fig. (25): Stability Class for December 2014

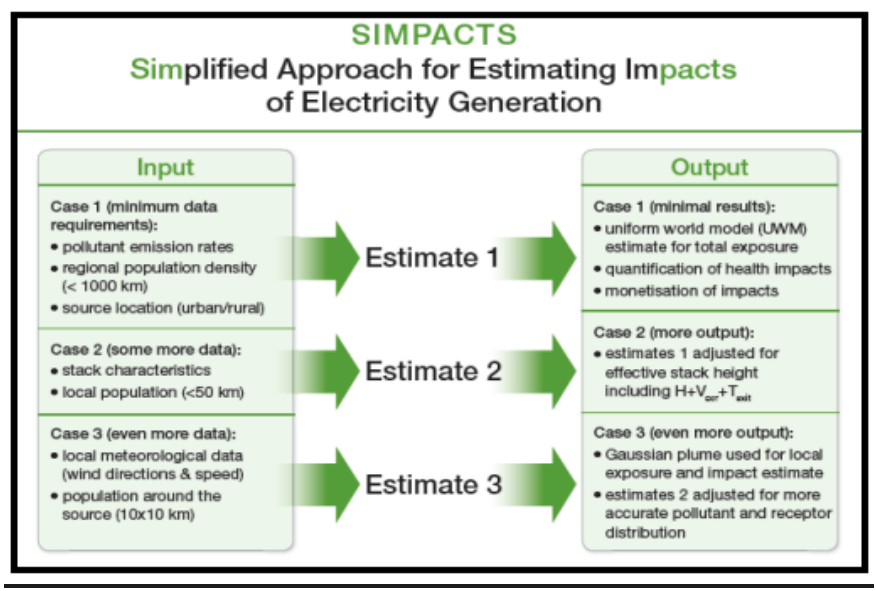

Fig: (26): Input and output data of the SIMPACTS

Results are evaluated through:

Model parameters

There are two stacks for the power plant with the following specification:

Table (2): Approx. location of the two stacks in UTM coordinates

Stack1 (766.015, 3448.7870)

Stack2 $\quad(766.015,3448.7034)$

\begin{tabular}{|c|c|c|c|}
\hline Stack height & $46.5 \mathrm{~m}$ & Regional Population (pers $/ \mathrm{km} 2)$ & 80 \\
\hline Stack diameter & $6.7 \mathrm{~meter}$ & Local Population (pers $/ \mathrm{km} 2)$ & 1013 \\
\hline Exit Temperature & $597^{\circ} \mathrm{K}$ & Radius of Local Domain $(\mathrm{km})$ & 56 \\
\hline Exi velocity & $48.5 \mathrm{~m} / \mathrm{s}$ & & \\
\hline
\end{tabular}

Source emission rate in case of using Natural Gas as fuel:
$\mathrm{NOx}$
$\mathrm{CO}$
$=30 \mathrm{~g} / \mathrm{s}$
$\mathrm{SO} 2$
$=14.97 \mathrm{~g} / \mathrm{s}$
$\mathrm{PM}$
$=0.3 \mathrm{~g} / \mathrm{s}$
$=2.02 \mathrm{~g} / \mathrm{s}$

Arab J. Nucl. Sci. \& Applic. Vol. 51, No.2 (2018) 


\section{Model Results:}

AIR PACKTS predicts seasonal dispersion of pollutant emitted from two stacks of Damanhour Electric -Power Plant, Alex Egypt. This plant uses mainly Natural Gas as fuel. The most likely pollutants emitted from stack of the plant are nitrogen oxides, carbon monoxide, sulfur oxides, and particulate matter.

Carbon monoxide concentrations range from $1 * 10$ 5 to $>0.01 \mathrm{mg} / \mathrm{m} 3$ which are far below the maximum permissible limit $(30 \mathrm{mg} / \mathrm{m} 3$ per hour in urban and industrial areas) according to the Egyptian Environmental Law 4/1994 (Table (3)) and its amendment modified by the ministerial decrees 1095/2011 and 710/2012. Nitrogen dioxide concentrations range from $1 * 10-5$ to $>0.01 \mathrm{mg} / \mathrm{m} 3$ which are equivalent to $(0.01$ and $10 \mu \mathrm{g} / \mathrm{m} 3$ respectively) and are far below the maximum permissible limit (300 $\mu \mathrm{g} / \mathrm{m} 3$ per hour in urban and industrial areas) according to law 4/1994. Sulfur dioxide concentrations range from $1 * 10-3$ to $>0.1$ $\mathrm{mg} / \mathrm{m} 3$ which are equivalent to $(1$ and $100 \mu \mathrm{g} / \mathrm{m} 3$ respectively) and are below the maximum permissible limit (300 $\mu \mathrm{g} / \mathrm{m} 3$ per hour in urban areas) according to law 4/1994 and do not constitute any measurable risk.

Figures (26-42) illustrate Contour map of the monthly average of $\mathrm{NOx}, \mathrm{CO}, \mathrm{PM} 10$ and SO2 Concentration distribution in $\mathrm{mg} / \mathrm{m} 3$ for December(Winter) , April(Spring), August(Summer) and October(Autumn). It is clear that all results are far below the AQL and do not constitute any measurable risk.

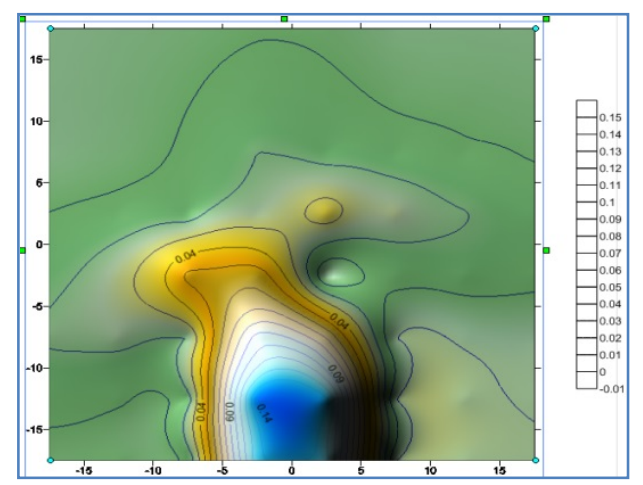

Fig. (27): NOX Concentrations for January 2014
Projection Dispersion Model for Carbon Monoxide emission from Damanhur Power Plant during winter, spring, summer and autumn are presented in Figures. (43-46).

\section{Risk assessment of accidental releases}

Aloha is an emergency response model, intended for rapid development by responders and for emergency planning. It incorporates source strength as well as Gaussian and heavy gas dispersion models [5, 6]. Model output is in both text and graphic form, and includes a "foot print" plot of the area downwind of a release where concentration may exceed user-set threshold levels. It can predict rates of chemical release from broken gas pipes, leaking tanks, and evaporating puddles, and can model the dispersion of both neutrally-buoyant and heavier than air gases.

This section describes hazards identification and calculations of end distance point as per AEGLS guidelines for selected scenarios using ALOHA model.

The following scenarios are simulated for an accident:

- Direct Source with stable atmospheric condition

- Direct Source with unstable atmospheric condition.

- Flammable gas escaping from pipe (not burning)

- Flammable gas escaping from pipe (burning) .

Configurations of the release Scenarios are presented in Tables $(4,5)$

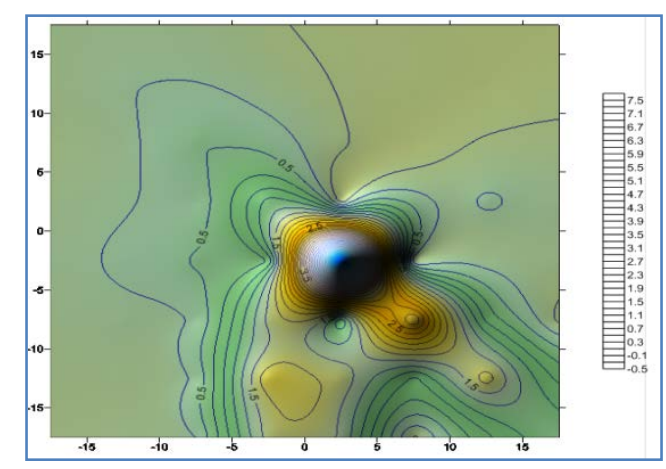

Fig. (28): Nox concentrations for May 2014 


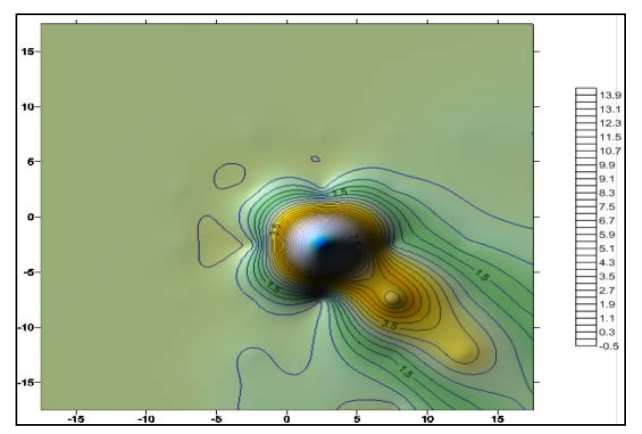

Fig. (29): Nox concentrations for July 2014

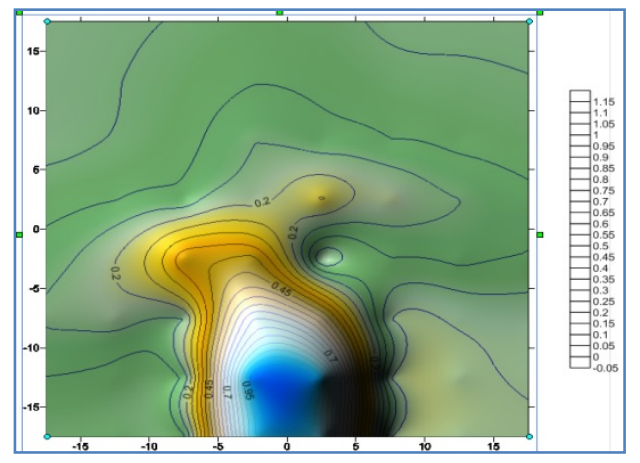

Fig. (31): CO Concentrations for January 2014

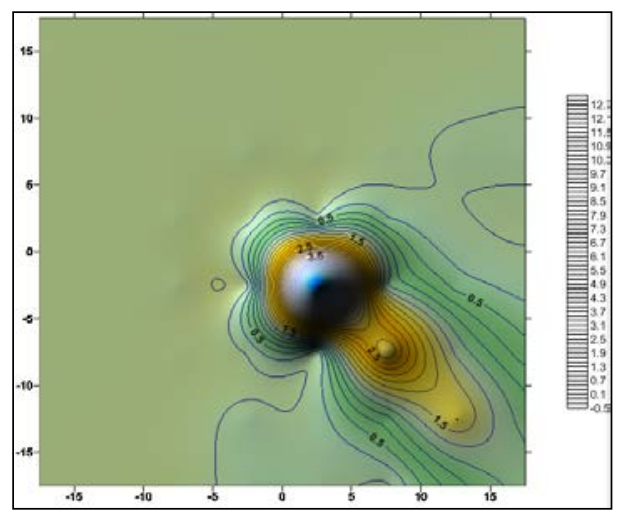

Fig. (33): CO Concentrations for July 2014

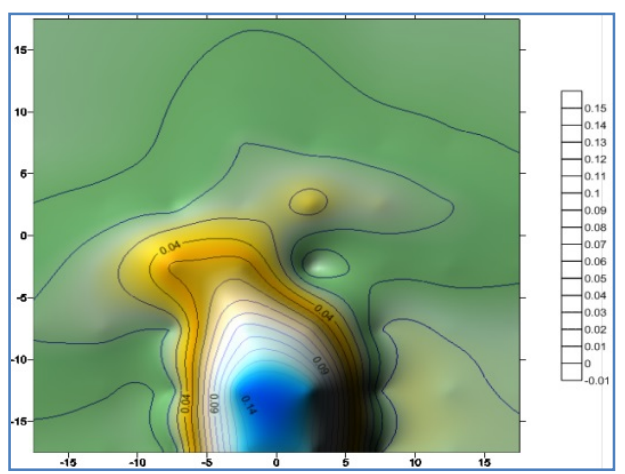

Fig. (35): PM 10 Concentrations for January 2014

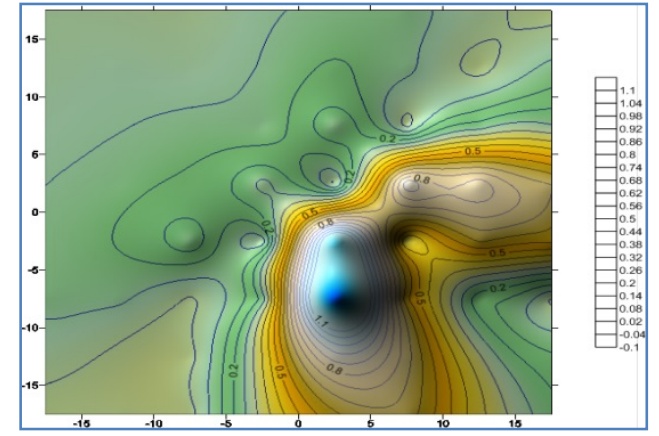

Fig. (30): Nox concentrations for November 2014

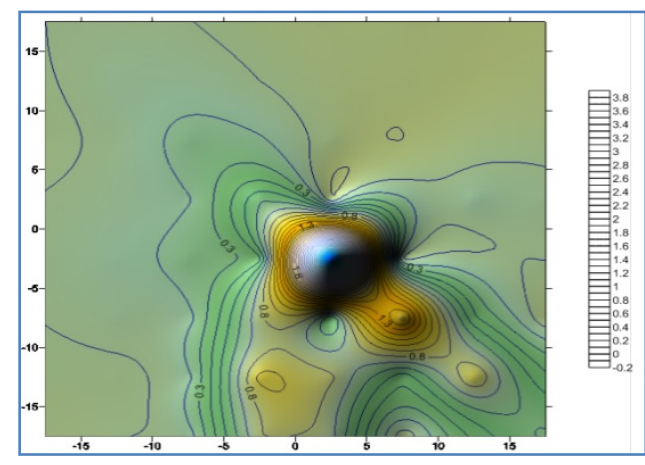

Fig. (32): CO Concentrations for May 2014

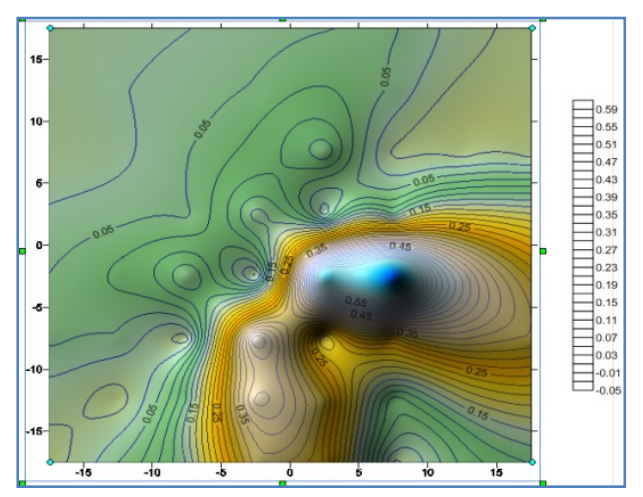

Fig. (34): CO Concentrations for November 2014

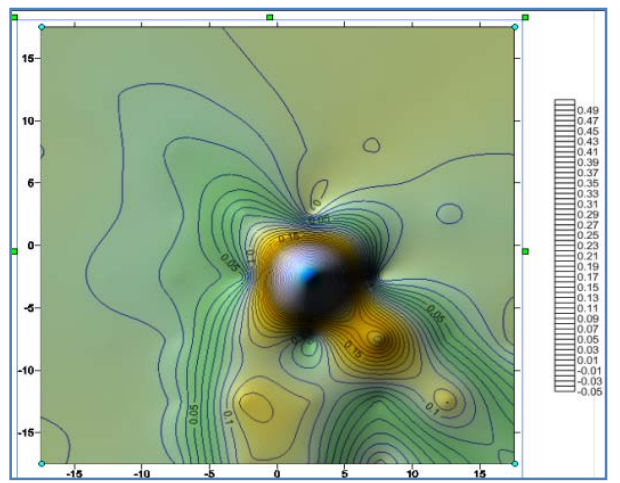

Fig. (36): PM 10 Concentrations for May 2014 


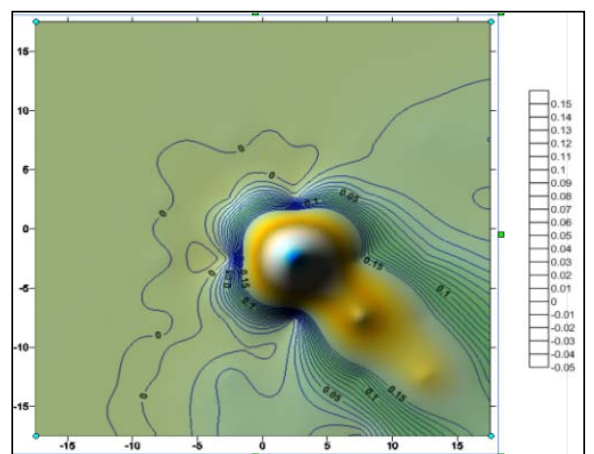

Fig. (37): PM 10 Concentrations for July 2014

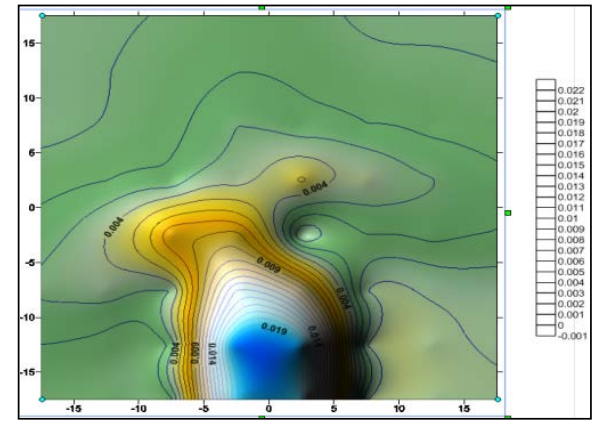

Fig. (39): SO2 Concentrations for January 2014

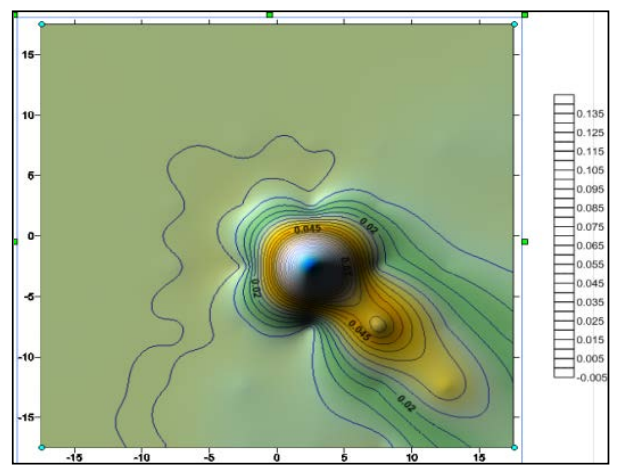

Fig. (41): SO2 Concentrations for July 2014

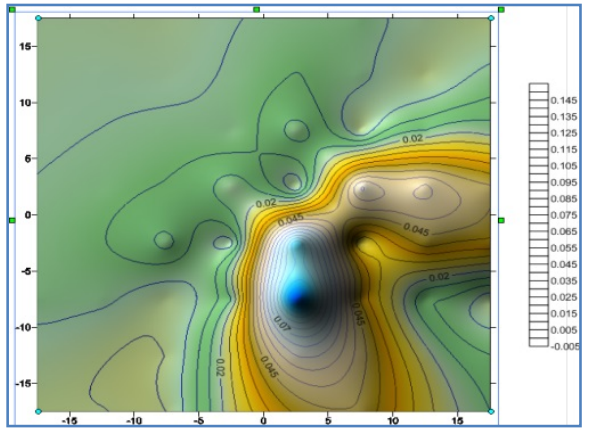

Fig. (38): PM 10 Concentrations for November 2014

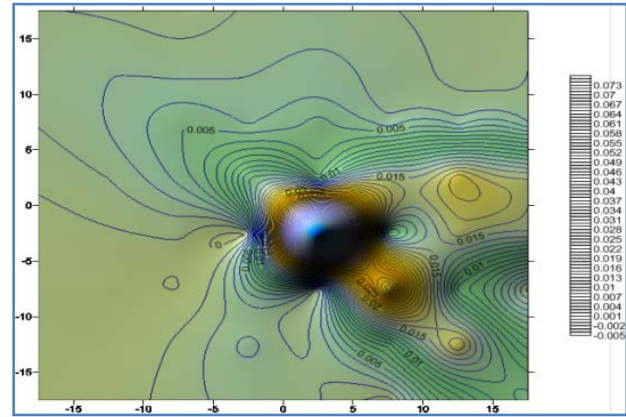

Fig. (40): SO2 Concentrations for May 2014

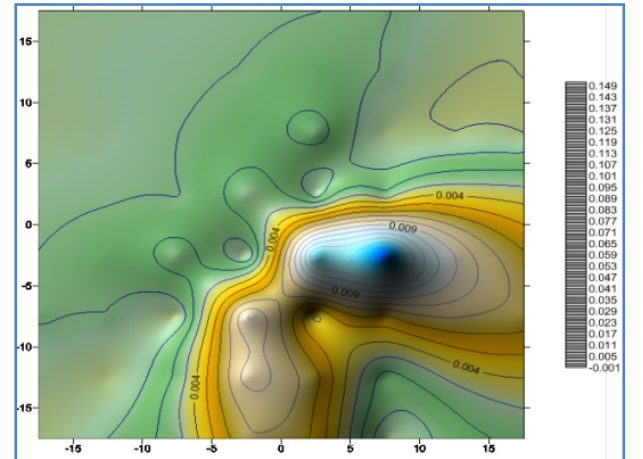

Fig. (42): SO2 Concentrations for November 2014

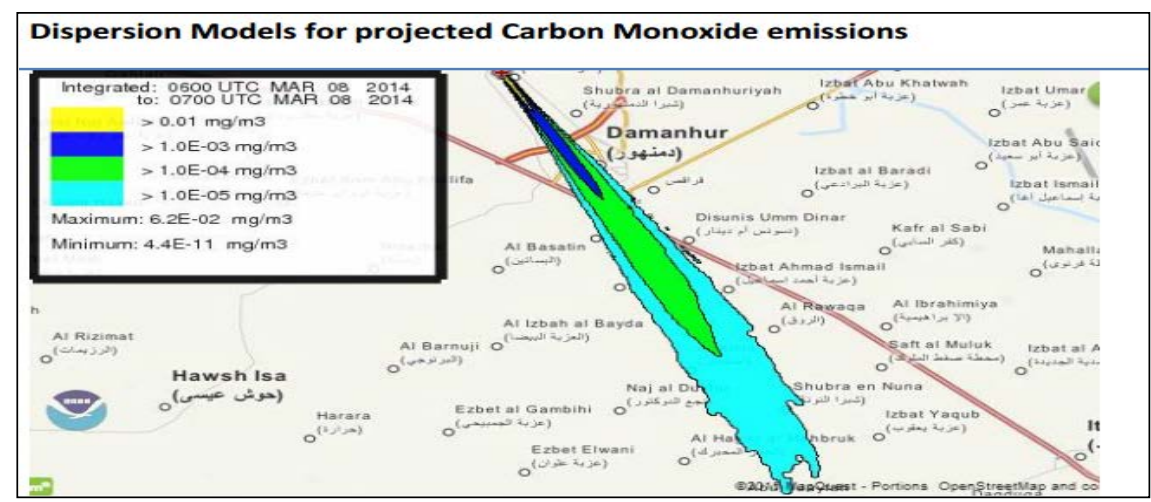

Fig. (43): Dispersion Model for CO emission from Damanhur Power Plant during winter 


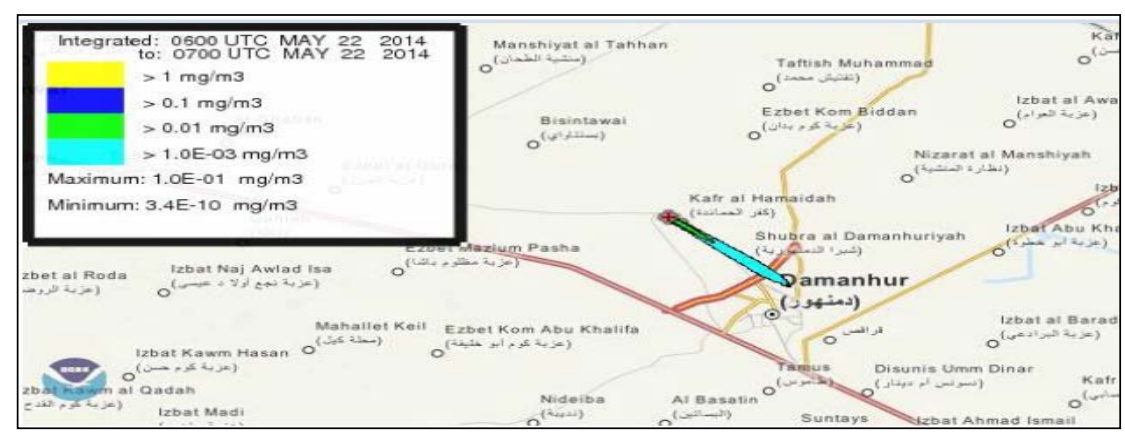

Fig. (44): Dispersion Model for CO emission from Damanhur Power Plant during spring

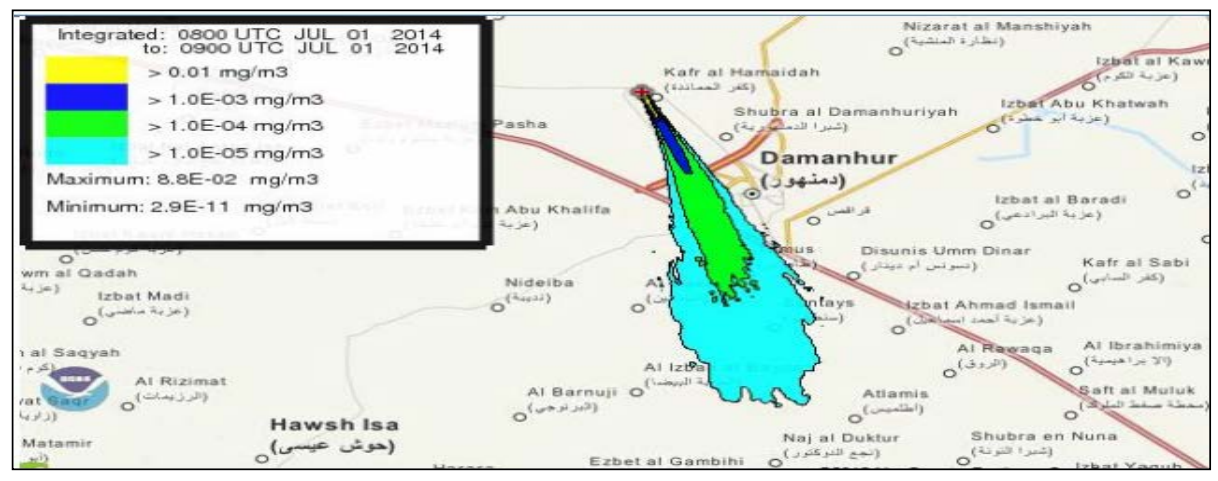

Fig. (45): Dispersion Model for CO emission from Damanhur Power Plant during summer

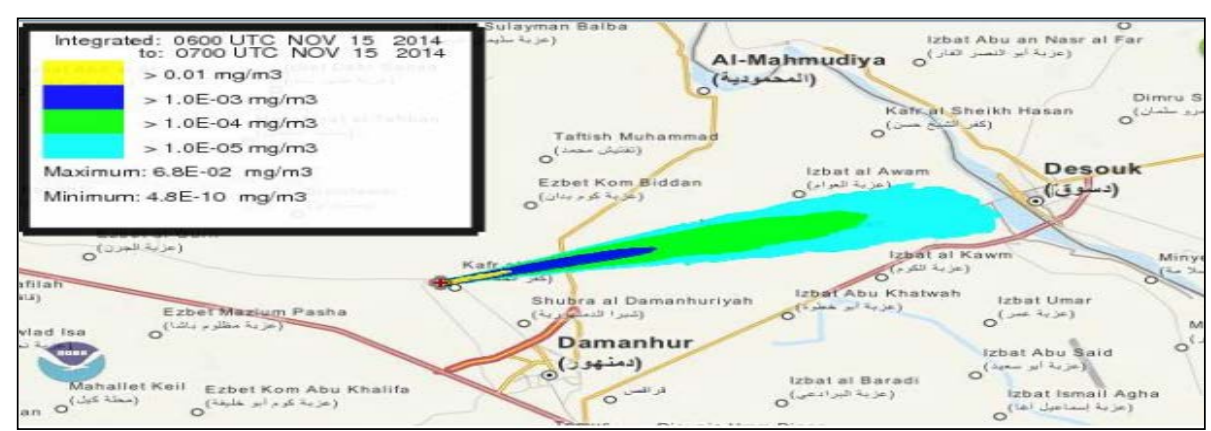

Fig. (46): Dispersion Model for CO emission from Damanhur Power Plant during autumn

Table (3): Maximum (permissible) limits for gaseous emissions from fuel combustion sources (energy generation) according to law 4/94[4]

\begin{tabular}{ccccc}
\hline \multirow{2}{*}{ Fuel Type } & \multicolumn{4}{c}{ Maximum limits for emissions $\left(\mathrm{mg} / \mathrm{m}^{3}\right)$} \\
& TSP & $\mathrm{CO}$ & $\mathrm{SO}_{2}$ & $\mathrm{NO}_{\mathrm{X}}$ \\
\hline Natural Gas & 50 & 100 & 150 & 500 \\
Diesel & 100 & 250 & 1300 & 500 \\
\hline
\end{tabular}


Table (4): Configurations of the release Scenarios $(1,2)$

\begin{tabular}{ccc}
\hline Hypothetical scenario of simulation & Scenario 1 & Scenario 2 \\
\hline Chemical Name & Nitrogen dioxide & Nitrogen dioxide \\
Building Air Exchanges Per Hour & 0.18 & 0.18 \\
Model of Release & Direct release & Direct release \\
Time of accident & December, day 4, hour 21 & December, day 8, hour 12 \\
Temperature & $19^{0} \mathrm{C}$ & $19^{0} \mathrm{C}$ \\
Relative humidity & $50 \%$ & $50 \%$ \\
Elevation of wind speed measurements & $10 \mathrm{~m}$ & $10 \mathrm{~m}$ \\
Atmospheric Stability Class & $\mathrm{F}$ & $\mathrm{B}$ \\
Wind Speed & $2.1 \mathrm{~m} / \mathrm{s} \mathrm{from} \mathrm{NE} \mathrm{at} 10 \mathrm{~m}$ & $1 \mathrm{~m} / \mathrm{sec} \mathrm{from} \mathrm{NE} \mathrm{at} 10 \mathrm{~m}$ \\
Cloud Cover & 5 & 5 \\
Ground roughness & Open Country & Open Country \\
Release Rate & $747,217 \mathrm{ppm}$ & $747,217 \mathrm{ppm}$ \\
Total amount released & $120 \mathrm{Kg} / \mathrm{min}$ & $120 \mathrm{Kg} / \mathrm{min}$ \\
Release duration & $7200 \mathrm{Kgs}$ & $7200 \mathrm{Kgs}$ \\
Model Run & $60 \mathrm{~min}$ & $60 \mathrm{~min}$
\end{tabular}

Table (5): Configurations of the release Scenarios $(3,4)$

\begin{tabular}{|c|c|c|}
\hline Hypothetical scenario of simulation & Scenario 3 & Scenario 4 \\
\hline Building Air Exchanges Per Hour & 0.18 & 0.18 \\
\hline Model of Release & $\begin{array}{c}\text { Flammable gas escaping from } \\
\text { pipe (not burning) }\end{array}$ & $\begin{array}{c}\text { Flammable gas escaping from } \\
\text { pipe (burning) }\end{array}$ \\
\hline Time of accident & month 12, day 10, hour 3 & December 10, 2014 at 03:20 \\
\hline Temperature & $12^{\circ} \mathrm{C}$ & $19^{0} \mathrm{C}$ \\
\hline Elevation of wind speed measurements & $10 \mathrm{~m}$ & $10 \mathrm{~m}$ \\
\hline Atmospheric Stability Class & $\mathrm{F}$ & $\mathrm{F}$ \\
\hline Wind Speed & $2.6 \mathrm{~m} / \mathrm{sec}$ from $220^{\circ}$ at $10 \mathrm{~m}$ & $2.6 \mathrm{~m} / \mathrm{sec}$ from $220^{\circ}$ at $10 \mathrm{~m}$ \\
\hline Cloud Cover & 5 & 5 \\
\hline Ground roughness & Open Country & Open Country \\
\hline Chemical Name & METHANE & METHANE \\
\hline Release Rate & $120 \mathrm{Kg} / \mathrm{min}$ & $120 \mathrm{Kg} / \mathrm{min}$ \\
\hline Total amount released & 66,171 Kgs & 7200 Kgs \\
\hline Release Duration & $60 \mathrm{~min}$ & $60 \min$ \\
\hline Ambient Saturation Concentration & $1,000,000 \mathrm{ppm}$ & $1,000,000 \mathrm{ppm}$ \\
\hline Ambient Boiling Point & $-161.5^{\circ} \mathrm{C}$ & $-161.5^{\circ} \mathrm{C}$ \\
\hline
\end{tabular}

Results summary of hazard evaluation are illustrated in Table (6). 
Table (6): Result Summary of Hazard Evaluation

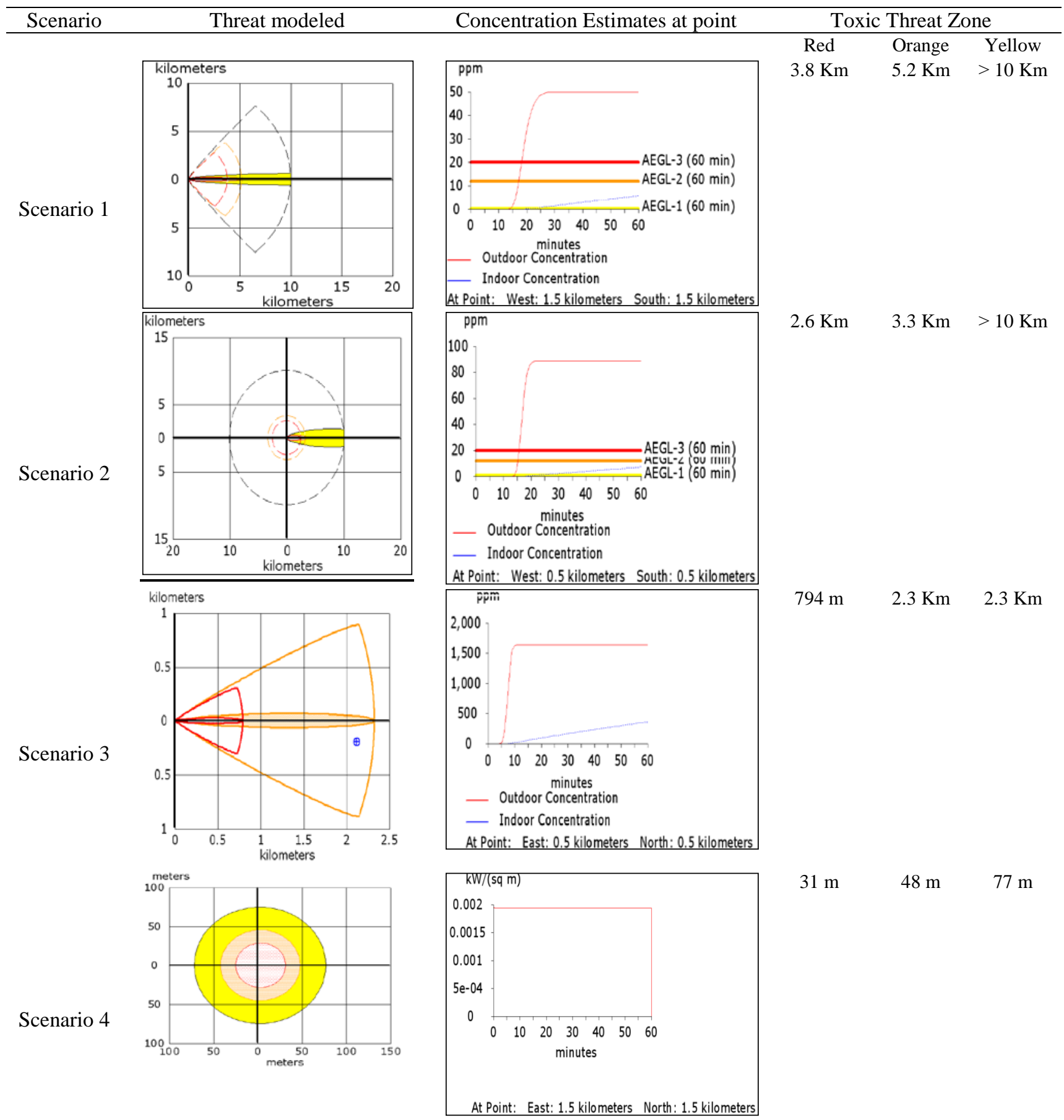

\section{Conclusion}

From the previous results, it is clear that the plant operation is safe on the environment and that the concentrations of all gases emitted from the stacks during operation are within the international limits and follow the Egyptian law limits.

\section{References}

1- Dmanhour Combined Cycle Power Plant ProjectSummary ESIA-07 2015.pdf.

2- Assessment tool on air pollution impacts from power production and its utilization for capacity building in the IAEA Member States, 17th User Interface Committee Meeting, Global Earth Observations, January 26, 2011, Vienna. 
3- STUDY OF THE ENVIRONMENTAL COSTS TO NUCLEAR POWER PLANTS USING THE PROGRAM SIMPACTS

4- The Egyptian environmental law No. 4 of year 1994.

5- http://www.epa.gov/cameo/what-cameo-softwaresuite\#ALOHA
6- ALOHA ${ }^{\circledR}$ (AREAL LOCATIONS OF HAZARDOUSATMOSPHERES) 5.4.4, Seattle, Washington, November 2013. 